\title{
A bivariable coupling model for river channel routing developed from the flow continuity equation and its application
}

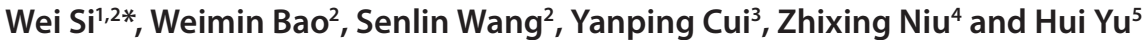 \\ 'Business School of Hohai University, Nanjing, 210098, China \\ ${ }^{2}$ College of Water Resources and Hydrology, Hohai University, Nanjing, 210098 China \\ ${ }^{3}$ Jiangsu Province Hydrology and Water Resources Investigation Bureau, Nanjing, 210029, China \\ ${ }^{4}$ Jiangsu NAIWCH Corporation, Nanjing, 210012, China \\ ${ }^{5}$ Lower Changjiang River Survey Bureau of Hydrology and Water Resources, Bureau of Hydrology, Changjiang Water \\ Resources Commissions, Nanjing, 210011, China
}

\begin{abstract}
In this study, a bivariable coupling model for river channel routing is presented. The proposed model is developed from the Priessmann 4-point implicit differential scheme with a weight coefficient of river flow continuity equation. It is based on the transformation of two different expression forms of river channel storage equation. Furthermore, we consider the impact of lateral inflow along the study river channel from another perspective. In this paper we deduct lateral inflow from the lower section instead of adding lateral inflow to the upper section. In order to be representative of geographical range, river channel characteristics, flood magnitude, hydraulic characteristics and time, the proposed model is tested in 38 river channels of 6 river systems in China by using observed data during flood season. The rationality of model structure and the validity of model simulation are examined comprehensively. Comparison between the proposed model and Muskingum model shows that the proposed model can improve the simulation accuracy. The results show that the simulation accuracy and stability of the bivariable coupling model is much better than that of the Muskingum model.
\end{abstract}

Keywords: bivariable coupling model, river flow routing, flow continuity equation, lateral inflow, Muskingum model

\section{INTRODUCTION}

Flood forecasting based on hydrological models is an important non-engineering measure for flood control and disaster reduction, which has received increasing attention from public, government and academic communities (Al-Safi and Sarukkalige, 2017; Yu et al., 2014). Efficient reservoir operation, river management, flood control and warning depend on reliable and accurate real-time flood forecasts (Cloke and Pappenberger, 2009; Hartnett and Nash, 2017; Si et al., 2015), which can be achieved by using hydrological models (Hostache et al., 2018). However, both conceptual models and distributed models need an accurate river flow routing module to calculate flood processes (Barati et al., 2012; Xu et al., 2017). In addition, the river flow routing model can calculate water level of flood control section, because water level is an important index and reference basis for flood control and flood risk management (JING et al., 2014; Wu et al., 2014).

There are many methods for flood routing, which are mainly divided into two categories: one is the hydraulic method based on Saint-Venant equations (Molls and Molls, 1998); another is the hydrologic method based on the water balance equation and river channel storage equation (Kubo, 1985). The physical meaning of the hydraulic method is clear, but it needs detailed data of river section, roughness and water surface slope. The hydrologic method focuses on the relationship among hydrological elements, which can simulate the main characteristics of a flood in the river channel; the hydrologic method is simple, practical and operable (Bao and Zhao, 2011). Therefore, the hydrologic

\footnotetext{
To whom all correspondence should be addressed.

e-mail: lindongsisi@163.com

Received 14 March 2018, accepted in revised form 7 March 2019.
}

method is more widely used for flood routing than the hydraulic methods (Fread, 1981).

The hydrologic flood routing method mainly includes the Muskingum method, linear regression method, runoff coefficient method, characteristic river length method and delay algorithm method. While the application of the Muskingum method is the most widely used due to the low requirement for river channel topography and roughness data (Singh and McCann, 1980; Tang et al., 1999), it has good performance in general river flood calculation. In addition, the Muskingum model with variable parameters has been applied in ungauged basins, utilizing the Muskingum model with variable parameters of wave travel time $\mathrm{KE}$ and weight coefficient of discharge XE based on the physical characteristics of the river reach and flood, including the reach slope, length, width, and flood discharge (Song et al., 2011).

The Muskingum routing method has been improved by many researchers since it was proposed in 1939 (Koussis, 2009; McCarthy, 1939). Most of these theoretical studies on the Muskingum method include model validation (Afzali and Niazkar, 2015), analysis of model structure, model structure improvement (Haddad et al., 2015), and calibration of model parameters by considering the temporally varying factors.

Muskingum model structure is usually validated by the comparisons between the observed and simulated discharge in the downstream section. The simulated discharge in downstream section can be obtained using the observed discharge in upstream section via Muskingum routing method (Afzali and Niazkar, 2015). Then, the magnitude and characteristics of the simulation errors are examined to evaluate the rationality of the model structure and the accuracy of simulation (Baláž et al., 2010; Chatila, 2003; Nash, 1959; Singh and McCann, 1980). 
Physical basis analysis of Muskingum model structure is conducted by analysing the relationship between the storage and release discharge of river channel, or by analysing the relationship between Muskingum river routing model and the differential model of Saint-Venant equations (BaymaniNezhad and Han, 2013). Therefore, the physical property of the Muskingum model was indirectly proved by analysing the physical basis of model structure (Cunge, 1969; Diskin, 1967; Wang et al., 2006).

In order to consider the non-linear relationship between river channel storage and outflow, structural improvement of the Muskingum routing method is mainly about the nonlinearization of a linear storage-release relationship and the study of model structure simplification (Kumar et al., 2011; Ponce, 1979).

Research on model parameter calibration and time varying factors is conducted by establishing the relationships between model parameters and time varying hydraulic factors such as wave travel time KE and weight coefficient of discharge XE (Perumal and Raju, 2001; Ponce and Yevjevich, 1978; Saxena and Perumal, 2014).

Many achievements have resulted from the intensive studies on these original and improved Muskingum routing methods. The result reveal that most of these methods can only be applied in the river channel which has a stable stage-discharge curve. However, the traditional Muskingum model cannot provide accurate simulations when applied in river channels with unstable stage-discharge curve or in tidal channels without stage-discharge curve (Bao et al., 2009; Bao et al., 2010; Bao et al., 2007; Si-min et al., 2009).

There are great differences between hydrological methods and hydraulic methods in flood routing, especially in water level forecasting. For example, hydraulic methods need water level or discharge of upper and lower sections as boundary conditions. The hydraulic methods have no forecasting function, and even if they have forecasting function, the lead time will be lost. However, hydrological methods only require the cross-section survey data of flood control section, and can forecast the future water level process well (Bao et al., 2018; Zhang and Bao, 2012).

In order to solve the abovementioned problem relating to the Muskingum routing model, we propose a bivariable coupling model of universal applicability for river channel routing in this work. The method is based on the river channel storage equation and the differential scheme of river flow continuity equation with consideration of lateral inflow. As far as the structure and basic theory of the model are concerned, the model proposed in this paper belongs to the hydrological method. Therefore, the advantage of this proposed model is that it has the function of forecasting, and does not need highprecision river channel survey data as a prerequisite.

\section{MODEL}

\section{Differential flow continuity equation}

If there is no lateral inflow, the one-dimensional flow continuity equation can be expressed by cross-sectional area $A$ and discharge $Q$ as:

$$
\frac{\partial A}{\partial t}+\frac{\partial Q}{\partial x}=0
$$

Using the Priessmann 4-point implicit differential scheme, the differential form of Eq. 1 can be expressed as follows:

$$
\begin{aligned}
\frac{\theta}{\Delta x} \Delta Q_{j+1}+ & \frac{1}{2 \Delta t} \Delta A_{j+1}= \\
& \frac{\theta}{\Delta x} \Delta Q_{j}-\frac{1}{2 \Delta t} \Delta A_{j}+\frac{1}{\Delta x}\left(Q_{j}^{i}-Q_{j+1}^{i}\right)
\end{aligned}
$$

where $\theta$ is the weight coefficient of Priessmann differential scheme; the subscript $j$ and $j+1$ represent the upper and lower section, respectively; $\Delta Q=Q^{i+1}-Q^{i} ; \Delta A=A^{i+1}-A^{i}$; the superscript $i$ and $I+1$ represent the last and next time period, respectively. The ordinate $t$ is time; the horizontal ordinate $x$ is channel length. The meaning of superscripts and subscripts in Eq. 2 are shown in the schematic diagram in Fig. 1.

Lateral inflow comprises a large proportion of river channel storage during flood season. However, lateral inflow is not likely to be represented by a particular function; typically there is lack of data. In order to take into consideration lateral inflow in Eq. 2, a general treatment is to multiply the upper-stream section discharge and crosssectional area by an amplifier coefficient (Bao et al., 2010; Kumar et al., 2011). This means that the lateral inflow is considered by adding it into upper-stream section inflow. Actually, the lateral inflow is distributed along the river reach, and its impact on river storage is distributed along the river reach. Here, we propose to deduct the lateral inflow from the discharge of the lower cross-section, which is to multiply the lower-stream section discharge by a reducer coefficient. Then we can get a new differential equation of Eq. 1 as follows:

$$
\begin{aligned}
\frac{\theta}{\Delta x} \beta \Delta Q_{j+1}+ & \frac{1}{2 \Delta t} \beta \Delta A_{j+1}= \\
& \frac{\theta}{\Delta x} \Delta Q_{j}-\frac{1}{2 \Delta t} \Delta A_{j}+\frac{1}{\Delta x}\left(Q_{j}^{i}-\beta Q_{j+1}^{i}\right)
\end{aligned}
$$

where $\beta$ is the lateral inflow reducer coefficient, the other variables in Eq. 3 are as for Eq. 2.

The discharge and cross-sectional area of the lowerstream section include all of the information which can reflect the lateral inflow affected by river storage. Therefore, it is more reasonable to deduct the lateral inflow from the lower-stream section.

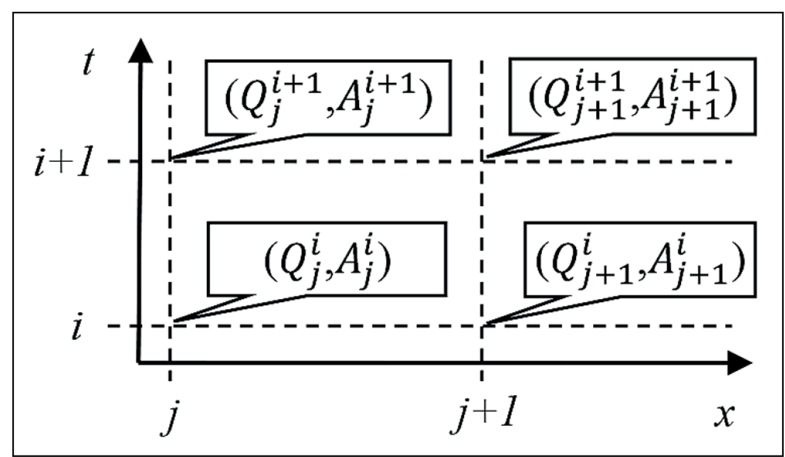

Figure 1

The schematic diagram of superscripts and subscripts in Eq. 2 


\section{Relationship analysis}

In order to get the solutions of Eq. 3, another equation is needed to describe the relationship between cross-sectional area and discharge. In hydrodynamics, the relationship between cross-sectional area and discharge is based on force balance. The simulation accuracy of the hydraulic method is not robust due to the large difference between the simulated and actual frictional resistance (Xiaoqin and Weimin, 2012; XiaoQin et al., 2009; Zhang and Bao, 2013). In hydrology, the storage discharge relation was proposed to develop the Muskingum routing method. However, this method is only appropriate for river channels with stable stage-discharge curve (BAO et al., 2009; Bao et al., 2010; Bao et al., 2007). In view of this, we tried to obtain the direct relationship between cross-sectional area and discharge by using the following two different expression forms of river channel storage equation; following this a bivariable coupling model for river channel routing can be established.

$$
\begin{aligned}
& W=L \bar{A} \\
& W=K \bar{Q}
\end{aligned}
$$

where $W$ is the storage of river channel, $L$ is the length of river channel, $\bar{A}$ is the average cross-sectional area of river channel, $K$ is the flow propagation time, $\bar{Q}$ is the average discharge of river channel. Based on Eq. 4 and Eq. 5, an equation between average cross-sectional area $\bar{A}$ and average discharge $\bar{Q}$ can be obtained as below:

$$
\mathrm{L} \bar{A}=\mathrm{K} \bar{Q}
$$

Equation 3 can be solved once the relations between $\bar{A}$ and $\bar{Q}$ and the corresponding elements of upper and lower cross section are known. For this purpose, the following two assumed equations are introduced to solve this problem.

$$
\begin{aligned}
& \bar{A}=\alpha A_{j}+(1-\alpha) A_{j+1} \\
& \bar{Q}=\chi Q+(1-\chi) Q_{j+1}
\end{aligned}
$$

where $\alpha$ is the weight coefficient of average cross section, $\chi$ is weight coefficient of average discharge. The storage-discharge relationship of the river routing model can be obtained by taking Eq. 8 into Eq. 5. The rationality of the Muskingum storage-discharge relationship has been widely demonstrated (Baymani-Nezhad and Han, 2013; Kumar, Baliarsingh and Raju, 2011; Perumal and Raju, 2001). Then the relationship between cross section and discharge can be described by Eqs 6 , 7 and 8 .

$$
\mathrm{L} \alpha \mathrm{Aj}+\mathrm{L}(1-\alpha) \mathrm{A}_{j+1}=K \chi Q_{j}+K(1-\chi) Q_{j+1}
$$

The rationality of the above structure has been studied by Koussis (2009) and Kumar et al. (2011).

\section{Model structure}

The temporal differential form of Eq. 9 can be expressed as follows:

$$
-K(1-\chi) \Delta Q_{j+1}+L(1-\alpha) \Delta A_{j+1}=K \chi \Delta Q_{j}-L \alpha \Delta A_{j}
$$

where $\Delta Q$ and $\Delta A$ are as defined for Eq. 1 .
In both Eq. 3 and Eq. 10, all of the variables on the right-hand side of the equations are known, while the left hand values are unknown. The bivariable coupling model is established by using these two equations in this study. The coefficient determinant of these two equations can be expressed as:

$$
\left|\begin{array}{cc}
\frac{\beta \theta}{\Delta x} & \frac{\beta}{2 \Delta t} \\
-K(1-\chi) & L(1-\alpha)
\end{array}\right|=\frac{\beta \theta}{\Delta x} L(1-\alpha)+\beta \frac{K(1-\chi)}{2 \Delta t}>0
$$

The above equation is tenable for any weighting coefficient value of $\alpha$ and $\chi$ within the range of $(0,1)$. The value of the determinant is $>0$, which means that Eq. 9 is effective. The discharge of lower-stream section can be obtained by the simultaneous solution of Eqs 3 and 9.

$$
Q_{j+1}^{i+1}=B_{0} Q_{j+1}^{i}+B_{1} \Delta Q_{j}+B_{2} Q_{j}^{i}+B_{3} \Delta A_{j}
$$

where $B_{0}, B_{1}, B_{2}, B_{3}$ are all constant coefficients which can be expressed by parameters $\alpha, \beta, \chi$, and $\theta$ as below:

$$
\begin{aligned}
B & =\frac{\theta \beta}{\Delta x}+\frac{\beta K(1-\chi)}{2 \alpha L \Delta t} \\
B_{0} & =1-\frac{\beta}{B \Delta x} \\
B_{1} & =\left(\frac{\theta}{\Delta x}-\frac{\beta K \chi}{2 \alpha L \Delta t}\right) / B \\
B_{2} & =\frac{1}{B \Delta x} \\
B_{3} & =\left(\frac{\beta(1-\alpha)}{2 \alpha \Delta t}-\frac{1}{2 \Delta t}\right) / B
\end{aligned}
$$

\section{APPLICATION}

\section{Data description}

In order to fully evaluate the rationality of model structure and the validity of model application, we selected river channels based on the following two principles in this study:

- River channels should represent a wide range of hydraulic and cross-section characteristics.

- In view of the simplified method for dealing with lateral inflow in this study, the lateral inflow area and the proportion of lateral inflow should not be too large. If the proportion of lateral inflow is too large, this simplified processing method will likely result in a large simulated error.

According to the above principles, we selected river channels with different hydraulic and section characteristics for this study. These river channels are located in water systems all over the country (Yangtze River, Yellow River, Huaihe River, Liao River, Songhua River and an inland river channel of Tarim River). The river channel properties and data series used in this study are presented in Table 1, with river channels arranged in ascending order according to the river length. The locations of these study river channels are shown in Fig. 2. In order to avoid the influence of changes 
in cross-section characteristics on data consistency, the selected data series should be as continuous as possible.

The selected data used for calibration and validation were all in flood season, with the duration of the flood event as long as possible (the shortest flood event lasted 10 days, while the longest is 20 days). The time interval of flood event data is $0.5 \mathrm{~h}$. Since the time interval of the observed data we used was very short $(0.5 \mathrm{~h})$, it was difficult to collect data for many flood events (only 8 or 10 flood events in a river channel).

\section{RESULTS AND ANALYSIS}

The Muskingum river flow routing model can be expressed as follows:

$$
Q_{j+1}^{i+1}=C_{0} Q_{j}^{i+1}+C_{1} Q_{j}^{i}+C_{2} Q_{j+1}^{i}
$$

In order to test the performance of the bivariable coupling model, we used the same data series for both the Muskingum

\begin{tabular}{|c|c|c|c|c|c|}
\hline \multicolumn{6}{|c|}{$\begin{array}{c}\text { TABLE } 1 \\
\text { The property and data series of river channel }\end{array}$} \\
\hline River code & River system & River channel & Length (km) & Data (year) & Flood event \\
\hline 1 & Xinan River & Xialaxian-Lahelian & 13 & $1979-1980$ & 8 \\
\hline 2 & Yangtze River & Hongya-Jiajiang & 26 & $2008-2012$ & 9 \\
\hline 3 & Qiantang River & Misai-Changfeng & 30 & 1987-1989 & 9 \\
\hline 4 & Jinsha River & Mujiaqiao-Heqing & 32 & $2008-2009$ & 8 \\
\hline 5 & Yellow River & Xiaochuan-Shangquan & 33 & $2010-2011$ & 9 \\
\hline 6 & Fen River & Yitang-Shitan & 38 & $1967-1969$ & 8 \\
\hline 7 & Jing River & Zhangjiashan-Taoyuan & 49 & 1979-1981 & 9 \\
\hline 8 & Beijiang River & Feilaixia-Shijiao & 50 & $2007-2008$ & 8 \\
\hline 9 & Wujiang River & Xiangyang-Yangzhang & 51 & 2011-2012 & 9 \\
\hline 10 & Huangshui River & Ledu-Minhe & 54 & 2010-2012 & 8 \\
\hline 11 & Yangtze River & Dashadian-Luojiahe & 56 & 1971-1973 & 9 \\
\hline 12 & Dongjiang River & Lingxia-Boluo & 59 & 2010-2012 & 8 \\
\hline 13 & Huangshui River & Tiantang-Liancheng & 60 & 2010-2012 & 9 \\
\hline 14 & Jinsha River & Wali-Luning & 61 & 1980-1982 & 9 \\
\hline 15 & Ganjiang River & Xiajiang-Ji'an & 66 & $2008-2010$ & 9 \\
\hline 16 & Xijiang River & Pingle-Shaoping & 67 & $2007,2009-2010$ & 8 \\
\hline 17 & Kuye River & Shenmu-Wenjiachuan & 67 & $1983-1985$ & 10 \\
\hline 18 & Wuding River & Dingjiagou-Baijiachuan & 70 & $1983-1985$ & 10 \\
\hline 19 & Hetian River & Heishan-Tonggu & 70 & $2008-2010$ & 9 \\
\hline 20 & Ganjiang River & Xiajiang-Zhangshu & 77 & $2008-2010$ & 9 \\
\hline 21 & Zishui River & Shaoyang-Lengshuijiang & 81 & 2011-2012 & 9 \\
\hline 22 & Liao River & Tieling-Mahushan & 85 & 1993-1994 & 8 \\
\hline 23 & Dongjiang River & Heyuan-Lingxia & 87 & 2010-2012 & 8 \\
\hline 24 & Yellow River & Shizuishan-Dengkou & 87 & 2010-2012 & 9 \\
\hline 25 & Qin River & Runcheng-Wulongkou & 91 & 1987-1989 & 9 \\
\hline 26 & Wei River & Beidao-Tashi & 94 & 2007-2009 & 9 \\
\hline 27 & Ganjiang River & Shishang-Waizhou & 100 & $1968-1969$ & 8 \\
\hline 28 & Yangtze River & Luding-Shimian & 103 & $2008-2012$ & 8 \\
\hline 29 & Yangtze River & Wutongqiao-Gaochang & 104 & 2008-2012 & 9 \\
\hline 30 & Fujiang River & Pingwu-Jiangyou & 126 & $2008-2011$ & 10 \\
\hline 31 & Hanjiang River & Xincheng-Xiaoshicun & 134 & $1965-1967$ & 10 \\
\hline 32 & Yellow River & Anningdu-Xiaheyan & 225 & $20,102,012$ & 8 \\
\hline 33 & Jinsha River & Luning-Xiaodeshi & 249 & 1980-1982 & 9 \\
\hline 34 & Zhujiang River & Wuzhou-Gaoyao & 306 & $2007-2011$ & 10 \\
\hline 35 & Jinsha River & Wali-Xiaodeshi & 310 & $1980-1982$ & 9 \\
\hline 36 & Jiulong River & Zhangping-Punan & 332 & 2008, 2011-2012 & 9 \\
\hline 37 & Jinsha River & Huadan-Pingshan & 352 & 1984-1986 & 10 \\
\hline 38 & Jinsha River & Batang-Shigu & 366 & $1980-1982$ & 10 \\
\hline
\end{tabular}




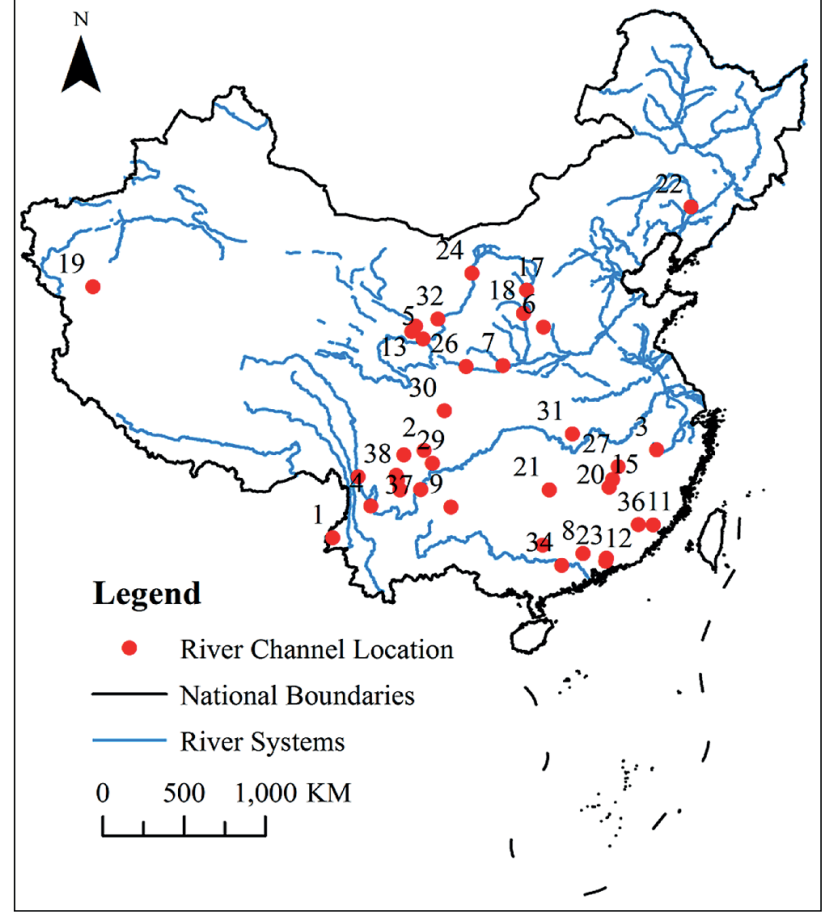

Figure 2

Locations of study river channels

model and the proposed model during the calibration period and validation period. Here, the Nash-Sutcliffe (NS) value was adopted to evaluate the model performance.

$$
N S=1-\frac{\sum_{k=1}^{M}\left(Q_{C}(k)-Q_{O}(k)\right)^{2}}{\sum_{k=1}^{M}\left(Q_{O}(k)-\overline{Q_{O}}\right)^{2}}
$$

where $\bar{Q}_{O}$ is mean value of observed series, $Q_{C}$ is the computed series, $Q_{O}$ is the observed series, $M$ is the number of data series. NS is used to evaluate the performance of the fit between calculated and observed flow. A larger value of NS indicates greater fitness of the model, the maximum value for which is 1.0. The collected data were divided into two parts, which were used for model parameter calibration and parameter validation, respectively.

The linearized parameter calibration method was adopted in this work. The linearized calibration method is a new optimization algorithm, which was developed to solve the theoretical problem of unrelated local optima produced in the nonlinear model parameter calibration by using the objective function based on error sum of squares. The calibrated parameter values are stable when using different initial parameter values via the linearized calibration method which can find the true parameter values without producing unrelated local optima. Furthermore, compared with the SCE-UA method and the simplex method, the linearized calibration method has higher calculation accuracy and convergence rate, and the parameter calibration results are also more stable, due to not being influenced by the different initial parameter values (Bao and Zhao, 2014). The linearized calibration method is an efficient, effective, and robust calibration method (Bao et al., 2013; Si et al., 2017).

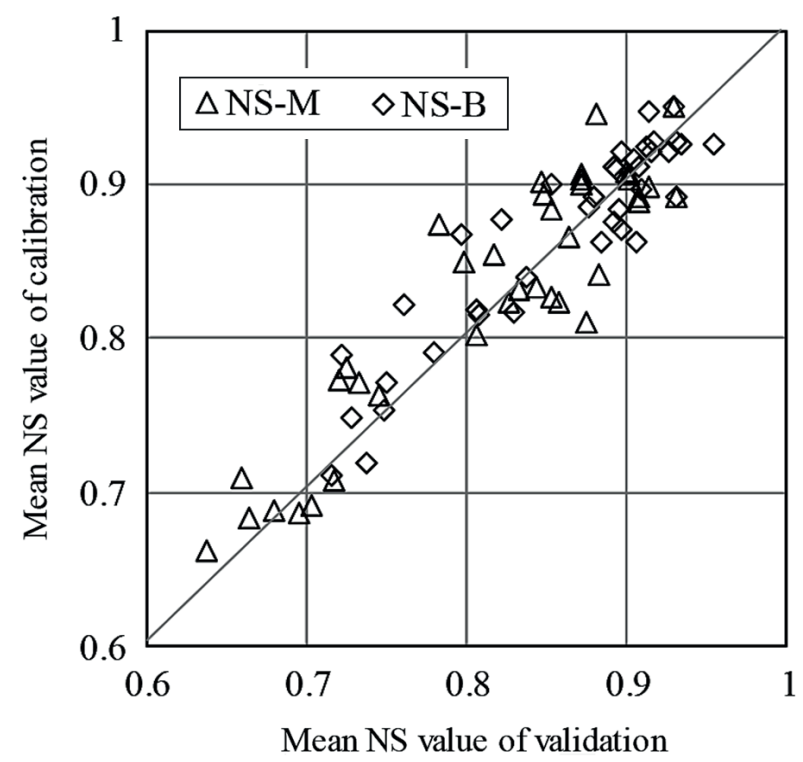

Figure 3

The relationship between mean NS value of calibration results and mean NS value of validation results of the two models

In order to illustrate that there is no systematic deviation during the study by the calibrated parameters of the two models, we presented NS values of the traditional Muskingum model and the bivariable coupling model in the same scatter plot (Fig. 3).

In Fig. 3, NS-M and NS-B represent the average NS value of Muskingum model and bivariable coupling model, respectively.

From Fig. 3, it can be seen that the results of the calibration period and validation period are evenly distributed on both sides of the $45^{\circ}$ line, which shows that the calibrated parameters of the two models are reasonable.

According to the analysis of the simulation results shown in Table 2 and Fig. 4, the results of the bivariable coupling model are better than those of the traditional Muskingum model, during both the calibration period and the validation period. In addition, Fig. 4 also shows that the stability of bivariable coupling model is better than that of the traditional Muskingum model. However, not all of the simulation results reach a higher NS value, the river channel length is treated as step length during practical application; a longer step length will cause a larger differential error in the continuous differential equation. In order to analyse this problem, we conducted a further statistical analysis and analysed the relationship between the mean NS value and the river channel length; the result is shown in Fig. 5.

Figure 5 shows that there is a significant correlation and trend between the simulation results and the river channel length. This shows that the interval inflow has a large influence on the simulation precision during flood routing. In general, the longer the river channel length, the larger the proportion of interval inflow, which is one of the important factors leading to the large difference error of the continuity equation. Although both the Muskingum model and the bivariable coupling model are influenced by the same difference error, simulation results of the proposed model are markedly better than the Muskingum method.

In order to show the application effect of the proposed model intuitively, the specific calculation results of a typical river channel (Wuzhou-Gaoyao) are presented in Table 3, and 


\begin{tabular}{|c|c|c|c|c|}
\hline \multicolumn{5}{|c|}{$\begin{array}{c}\text { TABLE } 2 \\
\text { Results simulated by different models }\end{array}$} \\
\hline \multirow{2}{*}{ River Number } & \multicolumn{2}{|c|}{ Calibration } & \multicolumn{2}{|c|}{ Validation } \\
\hline & NS-M & NS-B & NS-M & NS-B \\
\hline 1 & 0.871 & 0.931 & 0.907 & 0.928 \\
\hline 2 & 0.907 & 0.908 & 0.892 & 0.912 \\
\hline 3 & 0.846 & 0.896 & 0.901 & 0.921 \\
\hline 4 & 0.913 & 0.954 & 0.899 & 0.926 \\
\hline 5 & 0.853 & 0.879 & 0.883 & 0.892 \\
\hline 6 & 0.881 & 0.913 & 0.946 & 0.947 \\
\hline 7 & 0.929 & 0.929 & 0.951 & 0.951 \\
\hline 8 & 0.901 & 0.912 & 0.903 & 0.924 \\
\hline 9 & 0.843 & 0.884 & 0.833 & 0.862 \\
\hline 10 & 0.901 & 0.934 & 0.906 & 0.926 \\
\hline 11 & 0.883 & 0.909 & 0.842 & 0.897 \\
\hline 12 & 0.798 & 0.796 & 0.849 & 0.867 \\
\hline 13 & 0.745 & 0.807 & 0.763 & 0.816 \\
\hline 14 & 0.826 & 0.895 & 0.824 & 0.884 \\
\hline 15 & 0.899 & 0.915 & 0.908 & 0.921 \\
\hline 16 & 0.872 & 0.917 & 0.903 & 0.927 \\
\hline 17 & 0.816 & 0.876 & 0.854 & 0.885 \\
\hline 18 & 0.659 & 0.805 & 0.709 & 0.768 \\
\hline 19 & 0.875 & 0.905 & 0.811 & 0.862 \\
\hline 20 & 0.908 & 0.904 & 0.889 & 0.917 \\
\hline 21 & 0.857 & 0.897 & 0.824 & 0.871 \\
\hline 22 & 0.853 & 0.892 & 0.827 & 0.876 \\
\hline 23 & 0.783 & 0.822 & 0.874 & 0.878 \\
\hline 24 & 0.724 & 0.852 & 0.781 & 0.9 \\
\hline 25 & 0.848 & 0.891 & 0.893 & 0.912 \\
\hline 26 & 0.833 & 0.837 & 0.832 & 0.839 \\
\hline 27 & 0.871 & 0.894 & 0.9 & 0.91 \\
\hline 28 & 0.733 & 0.761 & 0.772 & 0.822 \\
\hline 29 & 0.931 & 0.931 & 0.892 & 0.892 \\
\hline 30 & 0.719 & 0.721 & 0.773 & 0.789 \\
\hline 31 & 0.805 & 0.829 & 0.803 & 0.817 \\
\hline 32 & 0.863 & 0.926 & 0.866 & 0.921 \\
\hline 33 & 0.716 & 0.727 & 0.708 & 0.748 \\
\hline 34 & 0.637 & 0.779 & 0.763 & 0.791 \\
\hline 35 & 0.695 & 0.715 & 0.687 & 0.711 \\
\hline 36 & 0.702 & 0.749 & 0.692 & 0.772 \\
\hline 37 & 0.679 & 0.748 & 0.688 & 0.753 \\
\hline 38 & 0.663 & 0.737 & 0.684 & 0.719 \\
\hline Mean & 0.816 & 0.852 & 0.831 & 0.862 \\
\hline
\end{tabular}
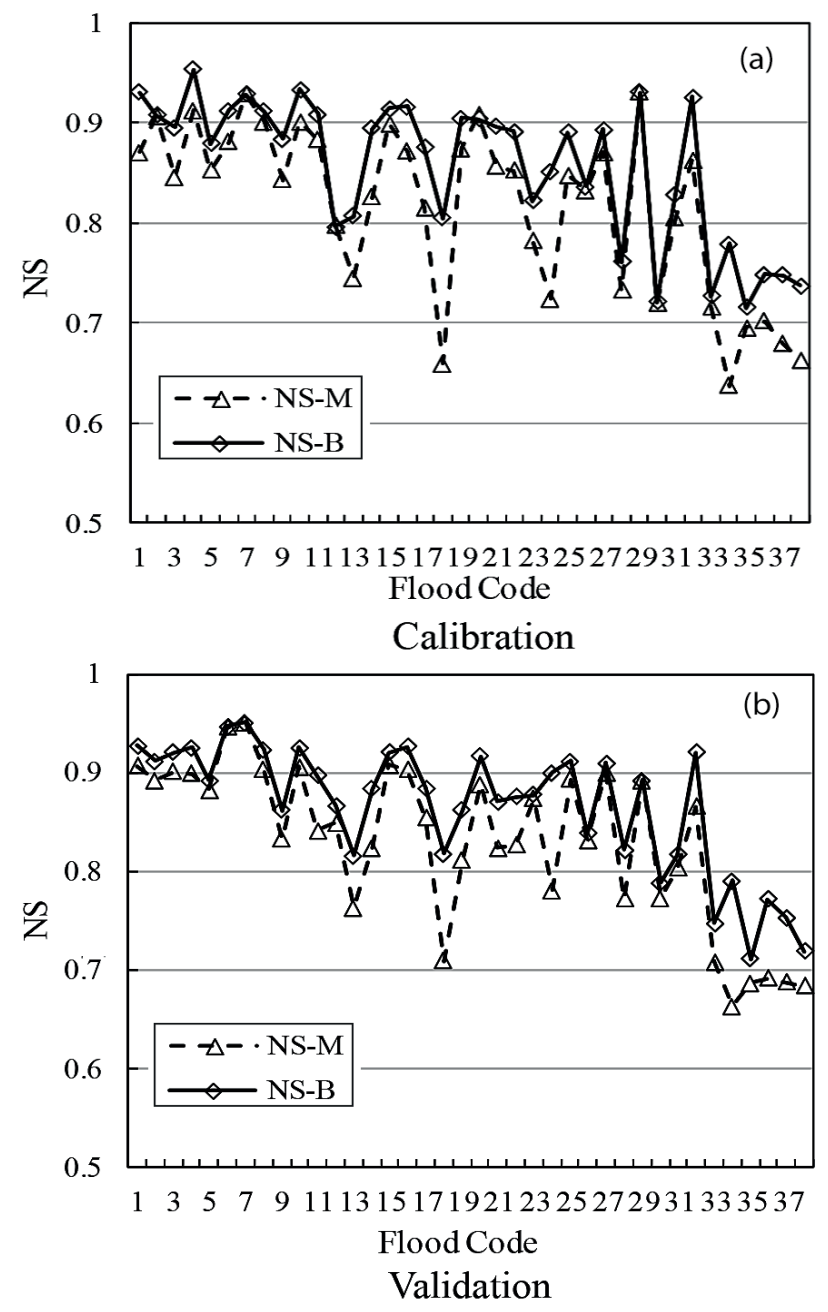

Figure 4

The average NS Value of the 38 river channels: (a) calibration result, (b) validation result

the observed and simulated results by different models for the 10 flood events are shown in Fig. 6.

The results in Table 3 and Fig. 6 show that the proposed model performs better than the Muskingum model. The overall performance indicates that the bivariable coupling model is more stable for river channels with different hydraulic characteristics, and the bivariable coupling model has a more reasonable structure, wider representativity and is more adaptive than the Muskingum model. Therefore, the structure rationality and simulation validity can be detected to a certain extent by using the same data series.

\section{CONCLUSIONS}

The bivariable coupling model for river channel routing is proposed in this paper. The proposed model is developed from the flow continuity equation based on the Pressimann 4-point implicit differential scheme with weight coefficient. In this work, the main innovation of the proposed model is the consideration of lateral inflow along the study river channel by deducting the lateral inflow from lower-stream section flow. 


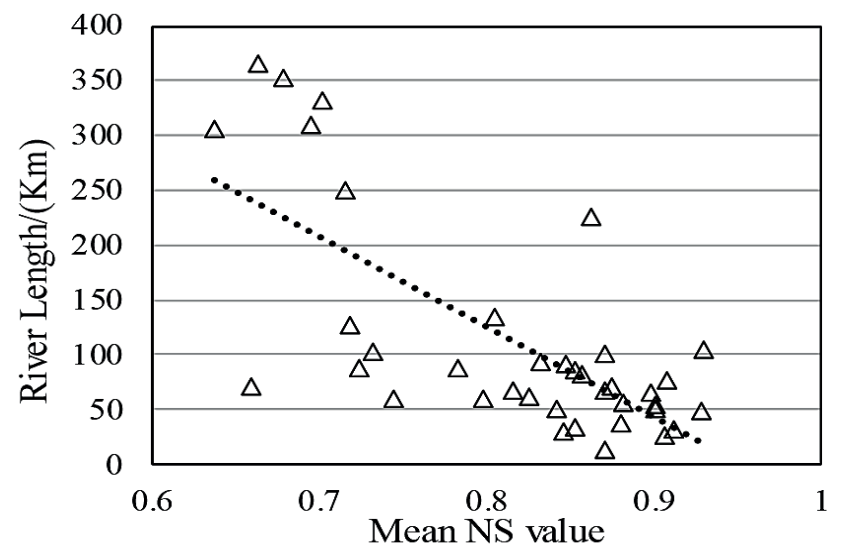

(a) NS-M of Calibration

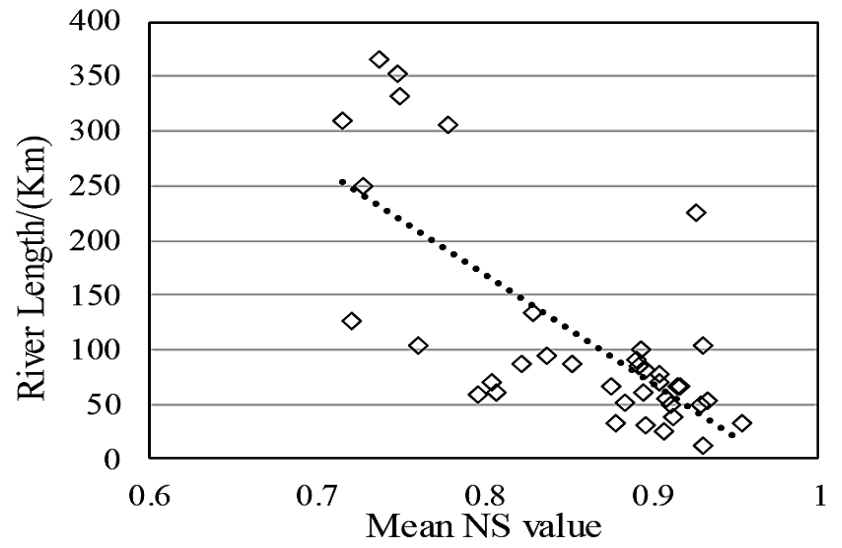

(c) NS-B of Calibration(a)

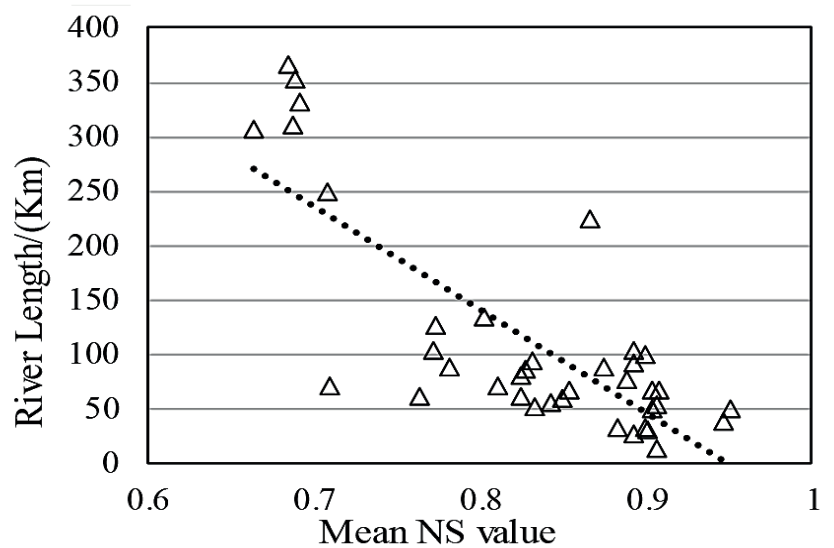

(b) NS-M of Validation

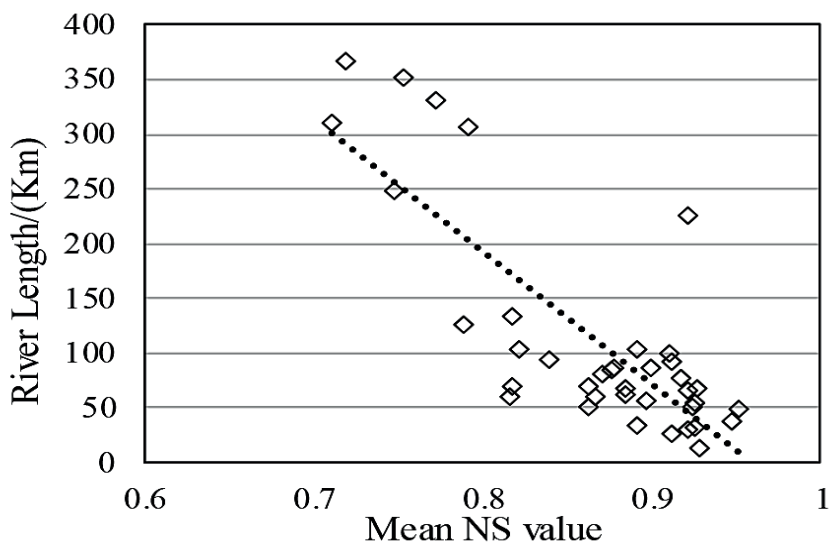

(d) NS-B of Calibration(b)

Figure 5

Changing trend of mean NS value with river channel length: (a) changing trend of Muskingum model in calibration period, (b) changing trend of Muskingum model in validation period, (c) changing trend of bivariable coupling model in calibration period, (d) changing trend of bivariable coupling model in validation period

The proposed model was fully verified in 38 river channels of 6 river systems in China by using observed data during flood season. The rationality of model structure and the validity of model simulation were estimated comprehensively. Comparisons between the proposed model and Muskingum model were also presented in this study. The results show that the simulation accuracy and stability of the bivariable coupling model is much better than that of the Muskingum model. The applicability of the bivariable coupling model is more general. In addition, the proposed model has the advantage of simple structure and stable performance.

Through this study, we also draw some conclusions on the applicability of the proposed model. We suggest that the river channel length should not be too long during the process of using this model. The river channel length is treated as step length during practical application; a longer step length will cause a larger differential error in the continuous differential equation. But even so, the proposed model is superior to the traditional Muskingum model. This conclusion also provides a theoretical basis and reference for the future application of the model. Further research will continue to improve the proposed model and demonstrate its applicability.

\begin{tabular}{|l|c|c|c|}
\hline \multicolumn{4}{|c|}{$\begin{array}{c}\text { TABLE 3 } \\
\text { Simulation results for Wuzhou-Gaoyao River channel by } \\
\text { different }\end{array}$} \\
\hline mlood code & Time period & NS-M & NS-B \\
\hline 1 & 1092 & 0.76 & 0.841 \\
\hline 2 & 726 & 0.698 & 0.814 \\
\hline 3 & 620 & 0.748 & 0.818 \\
\hline 4 & 839 & 0.718 & 0.813 \\
\hline 5 & 620 & 0.714 & 0.705 \\
\hline 6 & 1062 & 0.729 & 0.739 \\
\hline 7 & 259 & 0.673 & 0.829 \\
\hline 8 & 669 & 0.681 & 0.737 \\
\hline 9 & 474 & 0.669 & 0.748 \\
\hline 10 & 856 & 0.693 & 0.733 \\
\hline Mean & 738 & 0.708 & 0.777 \\
\hline
\end{tabular}



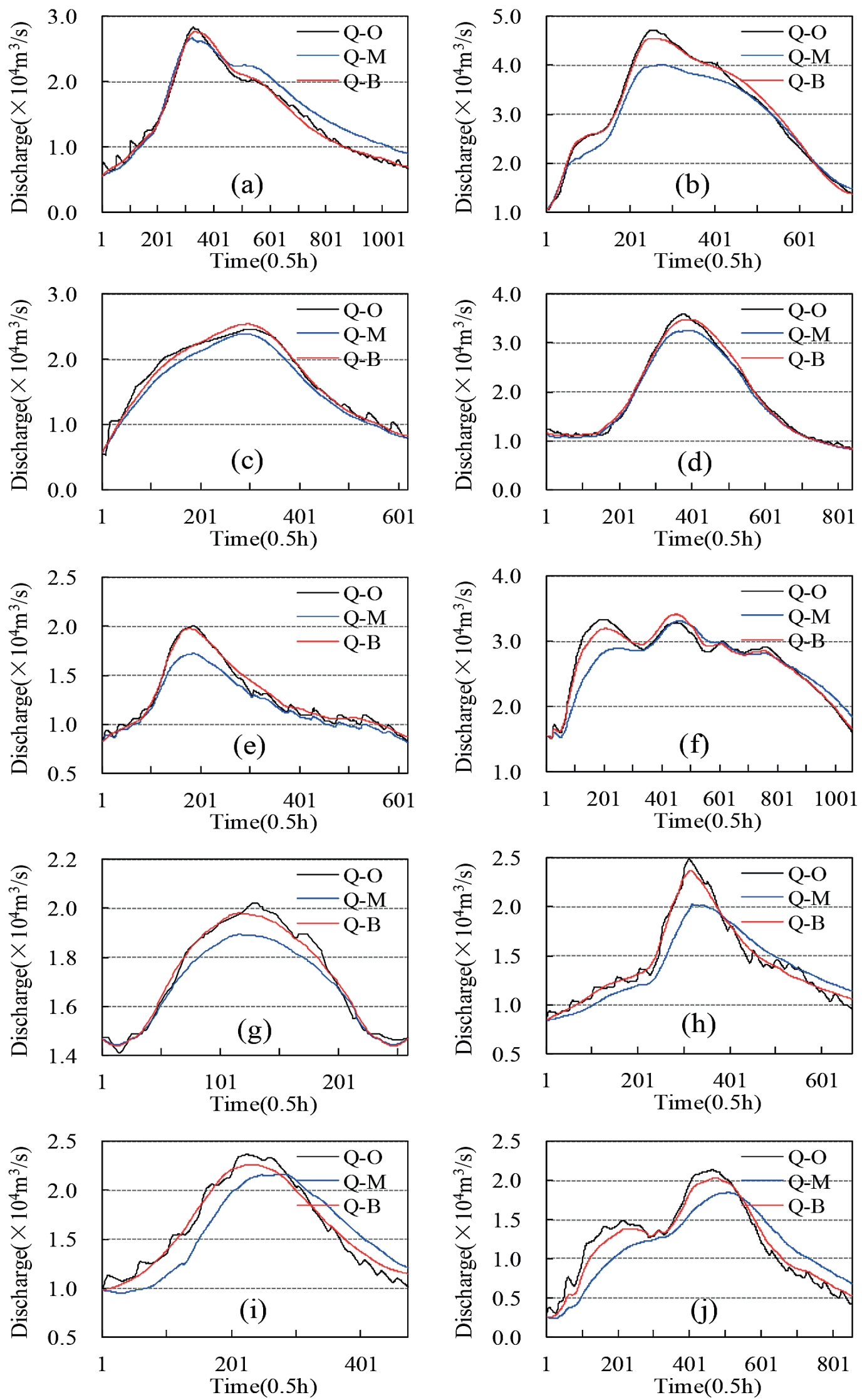

Figure 6

The observed hydrograph and simulated hydrograph by different model structure: $Q-O$ is the observed hydrograph, Q-M is the simulated hydrograph by Muskingum model, $Q-B$ is the simulated hydrograph by the bivariable coupling model 


\section{ACKNOWLEDGEMENTS}

We thank the editor and the three reviewers for their helpful comments and suggestions. This work was supported by National Natural Science Foundation of China (No.51709077), National Postdoctoral Foundation of China (2017M611679), Postdoctoral Foundation of Jiangsu Province (1701019A) and Open project fund of the Yellow River sediment Key Laboratory of the Ministry of water resources (201804).

\section{REFERENCES}

AFZALI SH and NIAZKAR M (2015) Muskingum flood routing model: Calibration review, Challenges and future trends. International Conference on Civil Engineering, Architecture and Urban Infrastructure, Tabriz, Iran.

AL-SAFI HIJ and SARUKKALIGE PR (2017) Assessment of future climate change impacts on hydrological behavior of Richmond River Catchment. Water Sci. Eng. 10 (3) 197-208. https://doi. org/10.1016/j.wse.2017.05.004

BAL Ž M, DAN ČOV M and SZOLGAY J (2010) On the use of the Muskingum method for the simulation of flood wave movements. Slovak J. Civ. Eng. 18 (3) 14-20. https://doi.org/10.2478/ v10189-010-0012-6

BAO HJ and ZHAO LN (2011) Hydraulic model with roughness coefficient updating method based on Kalman filter for channel flood forecast. Water Sci. Eng. 4 (1) 13-23.

BAO W, ZHANG X and QU S (2009) Dynamic correction of roughness in the hydrodynamic model. J. Hydrodyn. Ser. B 21 (2) 255-263. https://doi.org/10.1016/S1001-6058(08)60143-2

BAO W, ZHANG X, YU Z and QU S (2010) Real-time equivalent conversion correction on river stage forecasting with Manning's formula. J. Hydrol. Eng. 16 (1) 1-9. https://doi.org/10.1061/(ASCE) HE.1943-5584.0000279

BAO W, ZHAO C, WANG H and QU S (2007) Application of bi-directional stage routing model in a tidal reach. Methodology in Hydrology (Proceedings of the Second International Symposium on Methodology in Hydrology, held in Nanjing, China, OctoberNovember 2005). IAHS Publ. 311. 45-52.

BAO W and ZHAO L (2014) Application of linearized calibration method for vertically mixed runoff model parameters. $J$. Hydrol. Eng. 19 (8) 04014007. https://doi.org/10.1061/(ASCE) HE.1943-5584.0000984

BAO W, ZHOU J, XIANG X, PENG J and BAO M (2018) A hydraulic friction model for one-dimensional unsteady channel flows with experimental demonstration. Water 10 (1) 43. https://doi org/10.3390/w10010043

BAO WM, WEI SI and SI-MIN QU (2013) The linearized calibration method of non-linear function parameter. Chin. J. Comput. Mech. 30 (2) 236-241.

BARATI R, RAHIMI S and AKBARI GH (2012) Analysis of dynamic wave model for flood routing in natural rivers. Water Sci. Eng. 5 (3) 243-258.

BAYMANI-NEZHAD M and HAN D (2013) Hydrological modeling using effective rainfall routed by the Muskingum method (ERM). J. Hydroinf. 15(4) 1437-1455. https://doi.org/10.2166/ hydro.2013.007

CHATILA JG (2003) Muskingum method, EXTRAN and ONE-D for routing unsteady flows in open channels. Can. Water Resour. J. 28 (3) 481-498. https://doi.org/10.4296/cwrj2803481

CLOKE $\mathrm{H}$ and PAPPENBERGER F (2009) Ensemble flood forecasting: a review. J. Hydrol. 375 (3) 613-626. https://doi.org/10.1016/j. jhydrol.2009.06.005

CUNGE JA (1969) On the subject of a flood propagation computation method (Musklngum method). J. Hydraul. Res. 7 (2) 205-230. https://doi.org/10.1080/00221686909500264

DISKIN M (1967) On the solution of the Muskingum flood routing equation. J. Hydrol. 5 (3) 286-289. https://doi.org/10.1016/ S0022-1694(67)80108-2

FREAD D (1981) Flood routing: a synopsis of past, present, and future capability. VP Singh 521-542.
HADDAD OB, HAMEDI F, OROUJI H, PAZOKI M and LO ICIGA HA (2015) A re-parameterized and improved nonlinear Muskingum model for flood routing. Water Resour. Manage. 29 (9) 3419-3440. https://doi.org/10.1007/s11269-015-1008-9

HARTNETT M and NASH S (2017) High-resolution flood modeling of urban areas using MSN_Flood. Water Sci. Eng. 10 (3) 175-183. https://doi.org/10.1016/j.wse.2017.10.003

HOSTACHE R, CHINI M, GIUSTARINI L, NEAL J, KAVETSKI D, WOOD M, CORATO G, PELICH RM and MATGEN P (2018) Near-real-time assimilation of SAR-derived flood maps for improving flood forecasts. Water Resour. Res.54 (8) 5516-5535. https://doi.org/10.1029/2017WR022205

JING H-F, LI C-G, GUO Y-K, ZHU L-J and LI Y-T (2014) Numerical modeling of flow in continuous bends from Daliushu to Shapotou in Yellow River. Water Sci. Eng. 7 (2) 194-207.

KOUSSIS AD (2009) Assessment and review of the hydraulics of storage flood routing 70 years after the presentation of the Muskingum method. Hydrol. Sci. J. 54 (1) 43-61. https://doi. org/10.1623/hysj.54.1.43

KUBO N (1985) Comparison and evaluation of several numerical methods for hydraulic phenomena approximated by Saint Venant equations. Trans. Jap. Soc. Irrig. Drain. Rural Eng. 1985 71-83, a72.

KUMAR DN, BALIARSINGH F and RAJU KS (2011) Extended Muskingum method for flood routing. J. Hydro-environ. Res. 5 (2) $127-135$

MCCARTHY GT (1939) Unit hydrograph and flood routing. Conference of North Atlantic Division. US Army Corps of Engineers, New London, CT. US Engineering.

MOLLS T and MOLLS F (1998) Space-time conservation method applied to Saint Venant equations. J. Hydraul. Eng. 124 (5) 501508. https://doi.org/10.1061/(ASCE)0733-9429(1998)124:5(501)

NASH J (1959) A note on the Muskingum flood-routing method. J. Geophys. Res. 64 (8) 1053-1056. https://doi.org/10.1029/ JZ064i008p01053

PERUMAL M and RAJU KGR (2001) Field applications of a variableparameter Muskingum method. J. Hydrol. Eng. 6 (3) 196-207. https://doi.org/10.1061/(ASCE)1084-0699(2001)6:3(196)

PONCE VM (1979) Simplified Muskingum routing equation. J. Hydraul. Div. 105 (1) 85-91.

PONCE VM and YEVJEVICH V (1978) Muskingum-Cunge method with variable parameters. J. Hydraul. Div. 104 (12) 1663-1667.

SAXENA M and PERUMAL M (2014) Appraisal of overland flow modeling using HEC-HMS and a variable parameter Muskingum method. ISH J. Hydraul. Eng. 20 (1) 102-110. https://doi.org/10.1080 /09715010.2013.848607

SI-MIN Q, WEI-MIN B, PENG S, ZHONGBO Y and PENG J (2009) Water-stage forecasting in a multitributary tidal river using a bidirectional Muskingum method. J. Hydrol. Eng. 14 (12) 1299-1308. https://doi.org/10.1061/(ASCE) HE.1943-5584.0000120

SI W, BAO W, QU S, ZHOU M, SHI P and YANG X (2017) Modelling the effect of land use change on hydrological model parameters via linearized calibration method in the upstream of Huaihe River Basin, China. Water SA 43 (2) 275. https://doi.org/10.4314/wsa. v43i2.11

SI W, BAO WM and GUPTA HV (2015) Updating real-time flood forecasts via the dynamic system response curve method. Water Resour. Res. 51 (7) 5128-5144. https://doi org/10.1002/2015WR017234

SINGH VP and MCCANN RC (1980) Some notes on Muskingum method of flood routing. J. Hydrol. 48 (3) 343-361. https://doi. org/10.1016/0022-1694(80)90125-0

SONG XM, KONG FZ and ZHU ZX (2011) Application of Muskingum routing method with variable parameters in ungauged basin. Water Sci. Eng. 4 (1) 1-12.

TANG X, KNIGHT DW and SAMUELS PG (1999) Variable parameter Muskingum-Cunge method for flood routing in a compound channel. J. Hydraul. Res. 37 (5) 591-614. https://doi. org/10.1080/00221689909498519

WANG G-T, YAO C, OKOREN C and CHEN S (2006) 4-Point FDF of Muskingum method based on the complete St Venant 
equations. J. Hydrol. 324 (1) 339-349. https://doi.org/10.1016/j. jhydrol.2005.10.010

WU XL, XIANG XH, LI L and WANG CH (2014) Water level updating model for flow calculation of river networks. Water Sci. Eng. 7 (1) 60-69.

XIAOQIN Z and WEIMIN B (2012) A river stage correction approach using Fourier series. Hydrol. Res. 44 (4) 658-672.

XIAOQIN Z, WEIMIN B, ZHONGBO Y, SIMIN Q, CLUCKIE I, CHEN Y, BABOVIC V, KONIKOW L, MYNETT A and DEMUTH S (2009) Real-time Correction on the River Stage Forecasting with an Equivalent Stage Approach. IAHS Press, Hyderabad, India. $275-283$.
XU Z, LI L and ZHAO J (2017) A distributed eco-hydrological model and its application. Water Sci. Eng. 10 (4).

YU Z, YANG T and SCHWARTZ FW (2014) Water issues and prospects for hydrological science in China. Water Sci. Eng. 7 (1) $1-4$

ZHANG X-Q and BAO W-M (2012) Modified Saint-Venant equations for flow simulation in tidal rivers. Water Sci. Eng. 5 (1) 34-45. https://doi.org/10.1061/(ASCE)HE.1943-5584.0000526

ZHANG X and BAO W (2013) Hydrodynamic simulation in tidal rivers using Fourier series. J. Hydrol. Eng. 18 (11) 1408-1415. 